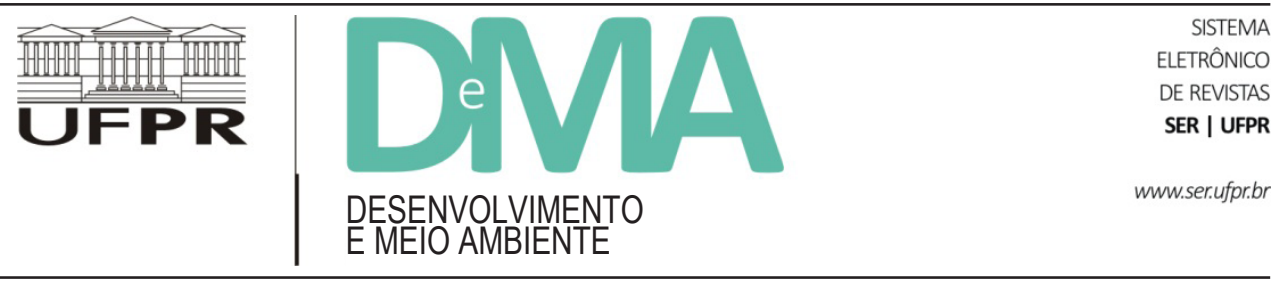

\title{
O Sistema Nacional de Cadastro Rural: história, limitações atuais e perspectivas para a conservação ambiental e segurança fundiária
}

\section{The National Rural Registration System: History, Current Limitations and Prospects for Environmental Conservation and Land Security}

\author{
André Arruda LASKOS ${ }^{*}$, Ademir Antonio CAZELLA², Paola Beatriz May REBOLLAR ${ }^{3}$ \\ ${ }^{1}$ Projeto Beija-Flor, Secretaria de Agricultura e Pesca do Estado de Santa Catarina, Florianópolis, SC, Brasil. \\ ${ }^{2}$ Universidade Federal de Santa Catarina (UFSC), Florianópolis, SC, Brasil. \\ ${ }^{3}$ Faculdade de Ciências Sociais de Florianópolis (FCSF), Florianópolis, SC, Brasil. \\ *E-mail de contato: arrudalaskos@hotmail.com
}

Artigo recebido em 22 de dezembro de 2014, versão final aceita em 25 de abril de 2016.

RESUMO: Os espaços rurais brasileiros desempenham papel importante na gestão das questões ambientais e sociais. Nestes espaços são tomadas decisões que afetam a conservação dos ecossistemas naturais remanescentes e a reprodução social das famílias de agricultores. O Brasil dispõe do Sistema Nacional de Cadastro Rural (SNCR), vinculado a um sistema de registro de imóveis que tem por objetivo dar segurança jurídica aos proprietários de imóveis, garantindo acesso a políticas públicas, além de possibilitar o planejamento do uso e da ocupação da terra e o monitoramento da legislação ambiental. No entanto, esse sistema cadastral é declaratório e grande parte das informações prestadas não são verificadas a campo pelas instituições públicas. Diante desse cenário, este artigo tem como objetivo reunir informações técnicas disponíveis na literatura a respeito do SNCR para analisar a sua utilização potencial como ferramenta de gestão socioambiental. Verificou-se que o sistema cadastral declaratório aplicado não permite que os dados cadastrais sejam utilizados para o planejamento e o monitoramento de políticas públicas socioambientais, dando margem a diversas fraudes associadas a pagamentos de impostos, mudanças de titularidade, acesso a crédito no sistema bancário, uso irregular de áreas públicas ou protegidas. É necessário que exista uma sólida base de dados oficiais sobre o território para que as instituições de gestão e os cartórios de registros de imóveis possam confrontar as informações prestadas pelos proprietários sobre os imóveis rurais para que o SNCR alcance seu objetivo.

Palavras-chave: espaço rural; gestão socioambiental; cadastro técnico multifinalitário.

ABSTRACT: The Brazilian rural areas play an important role in the management of environmental and social issues. In these areas decisions are made which affect the conservation of the remaining natural ecosystems and the social reproduction of farming families. Brazil has the National Rural Registration System (SNCR) linked to 
a land registry system that aims to give legal certainty for farms owners, ensuring access to public policies, and enabling the planning of the land's use and occupation and monitoring of environmental legislation. However, this registration system is declaratory and much of the information provided is not confirmed by public institutions. Therefore, this article aims to gather technical information available in the literature about the SNCR to analyze its potential use as an environmental management tool. The declaratory registration system applied was found not to allow registration data to be used for planning and monitoring of social and environmental policies, leading to several scams associated with tax payments, changes of ownership, access to credit in the banking system, and irregular use of public or protected areas.

Keywords: rural area; environmental management; multipurpose registry.

\section{Introdução}

A agropecuária cobre, aproximadamente, metade da área habitável do planeta (Clay, 2004). As decisões tomadas pelos agricultores na gestão de seus agroecossistemas afetam aspectos relacionados com a sociedade e com a natureza. Para realizar a gestão de uma área é necessário integrar interesses distintos sobre o uso e a ocupação do solo. No último século, diferentes autores apontaram a necessidade de regulação para evitar a exploração excessiva dos recursos naturais (Demsetz, 1967; Gordon, 1954; Hardin, 1968). A FAO (1998) vem advertindo constantemente sobre o problema da desertificação, em que atividades como desmatamento e pastoreio excessivo já implicam em milhões de áreas desertificadas na América Latina. Essas discussões estimularam governos de diversos países a promulgar políticas ambientais de regulação do uso do solo com o propósito de realizar a gestão de seus territórios.

Nossa sociedade enfrenta dois graves problemas relacionados aos espaços rurais. De um lado, como garantir a conservação dos remanescentes florestais e a aplicação efetiva da legislação ambiental sem promover o empobrecimento e o êxodo da população rural. De outro, como garantir segurança jurídica aos agricultores e suas famílias, possibilitando o acesso às diferentes políticas públicas de desenvolvimento rural existentes.
A eficiência de políticas ambientais e de desenvolvimento rural tem relação com o planejamento e o monitoramento que, por sua vez, estão relacionados com a existência de informações espaciais confiáveis. A obtenção e o gerenciamento desse tipo de informações é um desafio devido a sua complexidade e inter-relacionamento. Diante disso, muitos países utilizam sistemas cadastrais para tornar acessíveis os conhecimentos necessários para o planejamento e o monitoramento do uso do solo. Um sistema cadastral é um registro metódico de parcelas (terras, melhorias, direitos) que existem em determinado território composto por mapas temáticos (Eberl, 1982; Larsson, 1996; Loch \& Erba, 2007). Inicialmente, esses sistemas eram utilizados apenas para demarcação imobiliária. A evolução dos sistemas cadastrais permitiu sua utilização para o planejamento do uso do solo no que diz respeito ao desenvolvimento econômico, ao bem-estar social e ao equilíbrio ecológico (Larsson, 1996; Loch \& Erba, 2007).

Um sistema cadastral contendo informações sobre os imóveis, os proprietários e o uso e ocupação do solo pode ser utilizado como ferramenta de planejamento e monitoramento na medida em que permite responder a questões sobre quem são os ocupantes, quais suas potencialidades, necessidades e ações ambientais; o que está ocorrendo no local, indicando os tipos de ocupação que existem no território (residencial, comercial, industrial, 
agricultura, institucional, turístico), informando sobre o padrão econômico local, o potencial de degradação ambiental, as tendências de ocupação ou abandono e a relação entre o uso e ocupação do solo e a aptidão agrícola local; quando determinadas ações são realizadas, demonstrando tendências de ocupação, degradação ambiental e, principalmente, possibilitando o monitoramento e a identificação de autores de crimes ambientais; onde é necessária a intervenção imediata das instituições públicas para evitar a degradação socioambiental, implantar políticas públicas com mais eficiência e reordenar a ocupação de uma determinada área.

O Brasil dispõe do Sistema Nacional de Cadastro Rural (SNCR), vinculado a um sistema de registro de imóveis, que tem por objetivo dar segurança jurídica aos proprietários de imóveis, garantindo acesso a políticas públicas, e possibilitar o planejamento do uso e ocupação da terra, além do monitoramento da legislação ambiental brasileira. No entanto, esse sistema cadastral é declaratório e grande parte das informações prestadas não são verificadas empiricamente pelas instituições públicas.

Diante desse cenário, este artigo tem como objetivo principal reunir informações técnicas disponíveis na literatura a respeito do Sistema Nacional de Cadastro Rural com o propósito de analisar a sua utilização como ferramenta de gestão socioambiental. A discussão parte de uma abordagem histórica do processo de gestão de terras desde o período colonial para, num segundo momento, abordar o sistema de cadastro de terras instituído no início dos governos militares. Em seguida, procura-se apontar as principais consequências socioambientais decorrentes da fragilidade do sistema de cadastro vigente, cujas informações são de caráter declaratório da parte dos produtores rurais. O penúltimo tópico apresenta o recém-criado cadastro ambiental rural com o propósito de ilustrar a falta de coordenação institucional existente no país que, ao invés de aprimorar a base cadastral existente, investe em novas iniciativas, quase sempre de forma desarticulada e sobrepondo ações. Nas considerações finais, procura-se apontar as principais lacunas que resultam dessa desarticulação e suas consequências no processo de planejamento e de reordenamento territorial.

\section{Elementos históricos da gestão pública dos espaços rurais brasileiros}

A colonização portuguesa no Brasil baseou-se na filosofia de estímulo à produção primária. A ocupação oficial do território brasileiro teve início com a implantação do sistema de Capitanias Hereditárias. Esse sistema foi adotado em muitas colônias portuguesas e estava baseado no princípio privatístico da propriedade (Loch \& Erba, 2007). Essas capitanias eram subdivididas em parcelas denominadas Sesmarias, com seu respectivo título, a Carta de Sesmaria. Essas parcelas, por sua vez, eram doadas a candidatos dotados de capacidade de gerenciamento e negociação, com a intenção de povoar o local, delegando poderes e privilégios conforme o estatuto da Capitania. A partir das Sesmarias, se ramificou a propriedade imobiliária brasileira (Loch \& Erba, 2007; Medeiros, 2002).

A demarcação das sesmarias foi um problema que perdurou por séculos. Entre as principais dificuldades, é possível citar as despesas com funcionários nomeados para a função de demarcação, bem como aquelas relacionadas com o desconhecimento do território colonial. Mesmo assim, continuaram a ser emitidas as cartas de sesmarias, baseadas em informações imprecisas. Isso levou a múltiplos problemas, como áreas com diferentes sesmeiros nomeados, ocupação de terras públicas e o surgimento 
de latifúndios caracterizados pela grande extensão fundiária com baixa ou nenhuma exploração produtiva (Marighela, 1980).

A ideia de estimular a produção primária e a ocupação do solo em território brasileiro por meio da concessão de Sesmarias persistiu até 1822 . Nesse ano, a resolução 76, de 17 de julho de 1822, suspendeu esse tipo de concessão. Segundo Loch \& Erba (2007), a partir daí a posse e a ocupação irregular de terras proliferam. Mesmo com a Constituição Imperial de 1824, essa situação não se resolveu. Diante disso, o Governo Imperial promulgou em 1850 a Lei de Terras (Lei 601, de 18 de setembro de 1850). Essa lei iniciou a construção de um sistema de organização administrativa das terras brasileiras a partir da discriminação entre terras públicas e privadas. Dispunha ainda sobre a compra e venda de terras devolutas do Estado e sobre a revalidação da posse da terra por título de Sesmarias, entre outros temas (Loch \& Erba, 2007).

A Lei de Terras foi regulamentada em 1854 pelo Decreto Imperial 1.318, de 30 de novembro. Com esse decreto foi criada a Repartição Geral de Terras Públicas, que tinha as seguintes atribuições: medir as terras públicas; legitimar as terras de particulares e a venda de terras públicas; instituir o regime de fiscalização de terras devolutas e criar o registro paroquial. Além disso, essa lei instituiu o Registro de Terras Possuídas, que obrigava todos os proprietários com títulos de propriedade ou posse a registrar suas terras. No entanto, não foi exigida a planta de medição no momento do registro. Em 1890, o Decreto 451B exigiu o registro de qualquer ato que modificasse a área em questão. Esse decreto dispunha ainda sobre a planta e a avaliação dos imóveis, estabelecendo a necessidade de fixação de marcos referenciais estáveis que permitissem a incorporação da planta da propriedade com a Carta Geral Cadastral, entre outros detalhes importantes (Loch \& Erba, 2007).
A legislação de terras implantada no Brasil, tanto no período colonial quanto após a independência, manteve como característica o controle do acesso à terra. Desde a concessão de sesmarias, que foram doadas apenas a agentes de confiança do Império Português, até a Lei de Terras de 1850, o sistema de organização administrativa das terras brasileiras dificultou o acesso à terra, que poderia se dar apenas por meio da concessão ou da compra e venda. Mesmo o Estatuto da Terra, que tem a revisão fundiária como principal objetivo, não foi capaz de superar esta característica de controle, que assegura o acesso à terra a produtores que detêm maior poder econômico. Ou seja, recursos financeiros para a compra ou regularização da propriedade por meio de processos judiciários que apresentam custos financeiros relevantes.

O sistema de organização administrativa das terras brasileiras embasado na Lei de Terras de 1854 perdurou até a década de 1960 . O início desta década foi marcado por importantes medidas correlacionadas à posse e uso da terra no país, decorrentes, em grande parte, das profundas desigualdades produzidas ao longo da história e do início de um processo de organização sociopolítica no meio rural. O surgimento das Ligas Camponesas na região nordeste do país, na década de 1950, representa a face mais visível desse processo de desigualdade, mas várias outras frentes de mobilização de menor envergadura política começaram a preocupar o governo brasileiro (Martins, 1995).

Em 1962 foi criada a Superintendência de Política e Reforma Agrária (SUPRA), com a finalidade de conhecer o espaço rural brasileiro (Muritiba \& Alencar, 2007). Dois anos depois, em 1964, foram constituídos o Instituto Brasileiro de Reforma Agrária (IBRA) e o Instituto Nacional de Desenvolvimento Agrário (INDA), em substituição à SUPRA. Segundo Oliveira (2008), esses órgãos estiveram 
envolvidos em diversas acusações de corrupção, grilagens de terra e facilitação na venda de terras para estrangeiros, principalmente na Amazônia.

Nesse período houve o golpe militar de 1964 e, entre as primeiras medidas adotadas pelo governo militar, a promulgação da Lei 4.504 de 1964, chamada de Estatuto da Terra, que regulamentou diversos aspectos relacionados com os direitos e obrigações referentes aos imóveis rurais. Essa lei assegurou a oportunidade de acesso à terra a todos como parte da política agrícola nacional, condicionada à sua função social; destacou a necessidade de zoneamentos e cadastros, envolvendo as terras públicas, particulares, de posse e devolutas, além de criar o Cadastro de Imóveis Rurais do Brasil sob a responsabilidade do IBRA (Loch \& Erba, 2007).

Em 1970, foi criado o Instituto Nacional de Colonização e Reforma Agrária (INCRA), por meio da fusão do IBRA, do INDA e do Grupo Executivo de Reforma Agrária (GERA), como uma entidade autárquica vinculada ao Ministério da Agricultura. Durante os governos militares, o INCRA focou suas atividades na colonização de terras, principalmente na Amazônia e no Centro-Oeste. A partir de 1985, surgiram debates sobre os resultados alcançados pelo INCRA e sobre sua pertinência em coordenar as políticas públicas ligadas à estrutura fundiária brasileira.

Segundo Freitas (2007), os números inexpressivos de assentamentos criados pela política de reforma agrária acabaram extinguindo o INCRA em 1987. Após a Constituição de 1988, o Congresso Nacional recriou o órgão, rejeitando o decreto-lei que o extinguira. Depois disso, a mudança mais significativa no órgão se deu em 1992, quando a Receita Federal ficou responsável pelo Imposto Territorial Rural (ITR), que era de responsabilidade do INCRA desde a sua fundação. Desse modo, a principal função do INCRA é a gestão da estrutura fundiária nacional.
Apesar da existência de instituições públicas de gestão do espaço rural brasileiro, persistem diversos problemas, tais como a ocupação ilegal de áreas protegidas (Área de Preservação Permanente, Reserva Legal, Unidades de Conservação); de áreas particulares (posses e grilagens) e a sonegação de impostos. No próximo tópico, pretende-se discutir especificamente o sistema de cadastro de terras, apontando suas principais fragilidades.

\section{O cadastro público dos espaços rurais brasileiros}

Desde o Estatuto da Terra de 1964, o Brasil dispõe oficialmente de um Cadastro Técnico de Imóveis Rurais para proporcionar às instituições públicas, empresas e proprietários rurais dados e informações cartográficas sobre os recursos naturais, titularidade, formas geométricas e potencialidades dos estabelecimentos, visando à conservação ambiental e ao desenvolvimento rural integrado. Por meio deste Estatuto, o INCRA (antes era o extinto IBRA) é o órgão público responsável pelo Cadastro.

O cadastramento é obrigatório por lei para todos os proprietários, titulares de domínio útil ou possuidores a qualquer título de imóvel rural. De acordo com Brito (2005), o cadastro foi implantado parcialmente em 1965 nos Estados de Santa Catarina, Rio Grande do Sul, Paraná, Guanabara, Rio de Janeiro e Espírito Santo, estendendo-se ao resto do país nos anos seguintes. Esse cadastro objetivava identificar zonas passíveis de desapropriação para reforma agrária, áreas que necessitassem de assistência técnica para agricultores desfavorecidos economicamente e localidades em fase de ocupação carentes de programas de colonização. Essas ações deveriam verificar, também, a situação dos agricultores no que se refere à posse de terras e identificar 
os principais focos de conflitos agrários no campo. Além disso, o levantamento cadastral serviria para determinar o preço máximo de arrendamento de terras, o qual não poderia ser superior a $15 \%$ do valor cadastral do imóvel e suas benfeitorias. Outra função do cadastro seria fornecer a base de dados para a tributação das terras agrícolas, considerando o valor do imóvel e de suas benfeitorias descritas no cadastro.

A partir da década de 1970, o recém-criado INCRA passou a ser responsável pelo Cadastro. Em 1972, a Lei 5.868/1972 instituiu o Sistema Nacional de Cadastro Rural. Nesse mesmo ano, foi realizado o primeiro cadastramento de imóveis rurais, contendo o levantamento de dados dos proprietários e outros tipos de detentores de terra, o cadastro de terras públicas, bem como a situação da produção agrícola. Esse levantamento não contemplou todos os estabelecimentos rurais brasileiros.

O SNCR deveria englobar o Cadastro de Imóveis Rurais (incluindo os imóveis com ou sem título de propriedade), Cadastro de Proprietários de Imóveis Rurais (identificando proprietários e posseiros), Cadastro de Arrendatários e Parceiros (identificando os usuários dos imóveis), Cadastro de Terras Públicas e o Cadastro Nacional de Florestas Públicas. Porém, somente o primeiro foi implantado. Em 1978, houve outro cadastramento, visando estabelecer coordenadas geográficas para cada imóvel de forma a permitir sua localização em mapas em escala pequena.

Ainda na década de 1970 foi implantado outro Cadastro, denominado Cadastro Técnico de Imóveis Rurais (CTIR), prioritariamente em áreas de interesse para reforma agrária. Nesse cadastro foram registrados a localização, as relações de vizinhança, a caracterização da situação jurídica e o uso dado às terras. Além dos cadastros federais, órgãos estaduais de terras também realizam cadas- tros rurais para fins de regularização fundiária e planejamento regional (Carneiro, 2000).

Até 1992, o cadastro existente não foi revisado ou ampliado. Nesse ano foi realizado outro cadastramento, quando foram solicitadas plantas dos imóveis com área superior a 1.000 ha. Atualmente, o cadastro de imóvel no SNCR é realizado por meio de ato declaratório do proprietário, foreiro, enfiteuta, usufrutuário ou posseiro em documento chamado Declaração de Propriedade de Imóvel Rural (DP). Uma vez cadastrado, o imóvel recebe o número da Certidão de Cadastro de Imóvel Rural (CCIR).

Apesar dessas ações, os esforços cadastrais nas áreas rurais brasileiras foram eventuais, não padronizados e sem planejamento prévio, o que impediu que o cadastro técnico de imóveis rurais deixasse de ser apenas declaratório (Carneiro, 2000; Loch \& Erba, 2007). Segundo Loch \& Erba (2007), um dos principais problemas do cadastro de terras no Brasil está na falta de ligação entre os registros de imóveis e os documentos cartográficos produzidos pelos profissionais de agrimensura. Assim, não é possível afirmar sobre a correlação entre a realidade do campo (a posse efetiva) e o direito adquirido (título de propriedade). Dessa forma, é difícil a intervenção dos órgãos públicos, principalmente no que se refere ao monitoramento, porque existem poucos dados confiáveis sobre a situação real das áreas rurais brasileiras.

Mais recentemente, a Lei 10.267 de 2001 tratou do georreferenciamento dos imóveis rurais. Essa lei representa um marco na direção de uma efetiva integração entre cadastro e registro de imóveis porque define a obrigatoriedade do registro de uma planta topográfica e do memorial descritivo do imóvel antes da realização de qualquer mudança de titularidade. A exigência de produtos cartográficos para compor o cadastro é extremamente importan- 
te para criar uma base confiável para elaboração, implantação e monitoramento de políticas públicas ambientais e de desenvolvimento rural.

\section{Problemas socioambientais derivados do cadastro declaratório no Brasil}

Como mencionado anteriormente, desde o início da colonização do Brasil, diversos títulos de propriedade ou de usufruto foram emitidos pelos governos federal e estaduais. O processo de registro sistemático de imóveis brasileiros teve início em 1850, com a aprovação da Lei de Terras, que impôs prazos para os possuidores de terras registrarem-nas, sob pena de perda de direitos sobre as terras concedidas. Nesse caso, os possuidores passariam a ser considerados posseiros e as terras, denominadas devolutas. Nessa época não existiam os cartórios e o registro de imóveis era realizado nas paróquias das igrejas locais. O vigário da igreja conferia os documentos, assinava o documento que registrava o imóvel e o arquivava na própria igreja. A partir de 1864, as posses também passaram a ser registradas nas igrejas (Guedes \& Reydon, 2012; Shigunov, 2005).

O Código Civil de 1916 criou os cartórios de registro imobiliário enquanto instituições públicas de caráter jurídico. A partir de então, a propriedade de imóvel só poderia ser adquirida legalmente após o registro nos cartórios oficiais. A Lei 6.015 de 1973, que dispõe sobre os registros públicos, definiu os procedimentos a serem seguidos pelos cartórios para o registro de imóveis. Segundo essa lei, o cartório deve criar um número de matrícula único para cada imóvel. Nessa matrícula, são registradas as certidões e demais documentos públicos emitidos pelos cartórios de registro civil (partilhas, inventários e aquisições) e os números referentes aos cadastros públicos brasileiros, como a CCIR vinculada. Na mesma matrícula são averbadas ou retificadas informações referentes ao imóvel, tais como coordenadas, ângulos e rumos magnéticos, confrontações e localização de áreas de preservação ambiental previstas pela legislação contidas no Ato Declaratório Ambiental (ADA) vinculado ao Instituto Brasileiro do Meio Ambiente e dos Recursos Naturais Renováveis. A garantia jurídica da propriedade do imóvel é atestada pelo documento denominado certidão de matrícula do imóvel.

Tanto o INCRA quanto os cartórios de registros de imóveis não dispõem de uma base de dados oficiais para confrontar as informações declaradas pelos proprietários de imóveis rurais. Sem essa base, não é possível verificar se as informações declaradas são verdadeiras. No caso do INCRA, somente os imóveis acima de quatro módulos fiscais são fiscalizados. A escolha dos imóveis a serem fiscalizados ocorre de forma aleatória, sendo eleitos por área de atuação. Além disso, a lei não obriga os proprietários de imóveis com menos de quatro módulos fiscais a atualizarem as formas de uso. Assim, os dados cadastrais de todas as propriedades e posses médias e pequenas não são confiáveis e não podem ser utilizados para a gestão socioambiental ou para a elaboração de políticas públicas, nem para monitoramento da aplicação da legislação ambiental.

Esse cenário inviabiliza uma gestão fundiária confiável, dando margens a fraudes diversas, como sonegação de impostos; venda de uma mesma terra a compradores diferentes; revenda de títulos de terras públicas a terceiros como se elas tivessem sido postas legalmente à venda por meio de processos licitatórios; falsificação e demarcação de terras compradas com extensão muito maior do que a originalmente adquirida; confecção ou adulteração de títulos de propriedade e certidões; anexação de 
terras públicas a terras particulares; venda de títulos de terras atribuídos a áreas que não correspondem aos mesmos; venda de terra pública, inclusive indígena e em áreas de conservação ambiental; remembramento de terras às margens das grandes estradas federais, que em anos anteriores haviam sido distribuídas em pequenos lotes para fins de reforma agrária a pequenos agricultores; venda de terra pública pela internet, como se os vendedores fossem seus reais proprietários, com base em documentação forjada. A declaração ao INCRA de uma área superior ou inferior à área real do imóvel pode ter por objetivo a redução de impostos, omissão de terras improdutivas, ampliação de área para obter maior financiamento e a grilagem de terras (Girardi, 2008). Não bastasse a fragilidade do atual SNCR, mais recentemente foi instituído um novo tipo de cadastro, cujo propósito principal consiste em monitorar a legalização das reservas ambientais no interior dos estabelecimentos rurais.

\section{Cadastro Ambiental Rural}

A desarticulação das medidas em curso ganhou um novo ingrediente com a recente criação do Cadastro Ambiental Rural (CAR). Esse novo registro de informações derivou-se de ferramentas desenvolvidas desde 2005 relacionadas a metodologias de sensoriamento remoto para identificar os desmatamentos da Amazônia Legal e com os primeiros projetos pilotos de cadastramento na região.

Em 2012 foram aprovados a Lei 12.651/2012 e o Decreto 7.830/2012, que substituem a Averbação da Reserva Legal nos cartórios pelo cadastro no CAR. Antes do cadastro, o produtor precisava contratar um profissional para elaborar o memorial descritivo e a planta topográfica, registrando os dados no cartório.
O CAR é obrigatório para todos os estabelecimentos rurais e deve registrar dados ambientais referentes à situação das Áreas de Preservação Permanente (APP), Áreas de Reserva Legal, florestas e remanescentes de vegetação nativa, Áreas de Uso Restrito e áreas consolidadas das propriedades e posses rurais do país.

O Novo Código Florestal e o advento do CAR possibilitam mais agilidade para o produtor pelo fato de o sistema ser on-line, além de agrupar diversas informações importantes do estabelecimento rural. Apesar dessas melhorias, podemos perceber alguns pontos limitantes do novo cadastro.

\subsection{Procedimentos técnicos: limitações e possibilidades de desenvolvimento}

Esse novo cadastro não obriga o proprietário a contratar um profissional da área técnica para a realização do cadastramento. Além disso, as informações cartográficas obtidas em campo apresentam divergência com o sistema disponibilizado para o registro de dados referentes às áreas ambientais protegidas, sendo necessárias correções manuais das informações. Ou seja, quando o levantamento topográfico em meio digital é importado para dentro do sistema do CAR, a área aparece deslocada na imagem de satélite. Assim, é necessário mover manualmente o polígono que define o imóvel a fim de que coincida com a imagem. Esse ato compromete completamente a precisão e a acurácia obtidas a campo pelas atividades de topografia, já que as coordenadas do polígono são alteradas pelo deslocamento manual. Por fim, a qualidade das imagens disponibilizadas no sistema do CAR não permite a visualização de detalhes necessários para o cadastramento de pequenas áreas. 
Alguns autores, a exemplo de Araújo \& Juras (2012), Camargo (2013) e Laudares et al. (2014), destacam diversos aspectos controversos desse sistema cadastral, como a falta de estrutura dos órgãos ambientais para manter adequadamente o sistema em funcionamento; a falta de segurança jurídica do sistema declaratório proposto pelo CAR quando comparado com o processo de averbação que conta com a anuência prévia do órgão ambiental; a dificuldade de combater as ocupações ilegais baseado em um sistema declaratório em adaptação; a grande quantidade de erros e imprecisões que o sistema do CAR pode provocar, que dificulta ainda mais a fiscalização e o monitoramento por parte dos órgãos ambientais.

Somam-se a isso as dificuldades que os agricultores familiares ainda encontram na adesão ao CAR, principalmente pelo aspecto operacional do cadastro e a precariedade dos serviços de internet em municípios pequenos e médios do país. A complexidade do problema aumenta para os povos e comunidades tradicionais, onde a informação não chega tão facilmente e as ações de sindicatos e órgãos públicos municipais quase sempre são ineficientes nesse campo do conhecimento. Ademais, o novo código não dispõe claramente sobre a aplicação do CAR nas diferentes situações territoriais. Esse cadastro foi implantado em maio de 2014 e os agricultores tiveram um ano para efetuar o cadastramento, porém essa data foi adiada para maio de 2016 devido à baixa adesão, o que já era previsto por lei. Segundo o jornal Valor Econômico (2016), 67,6\% dos estabelecimentos rurais tinham sido cadastrados até abril deste ano.

\section{Considerações finais}

O Cadastro é uma ferramenta essencial para a gestão territorial. Ele deve disponibilizar informa- ções precisas e confiáveis sobre o espaço físico, a situação jurídica da ocupação do solo, a condição socioeconômica do ocupante da terra e as condições ambientais do imóvel. Para tanto, é necessário que exista uma sólida base de dados para que as instituições de gestão e os cartórios de registros de imóveis possam confrontar as informações prestadas, sobretudo, pelos proprietários sobre seus imóveis rurais. Somente por meio dessa confrontação os dados dos cadastros públicos podem ser utilizados para o planejamento e o monitoramento das condições socioambientais do território brasileiro.

Ter essas informações disponíveis, atualizadas e conectadas é essencial para a tomada de decisão, o monitoramento e o planejamento de ações de ordenamento territorial. As constantes alterações na ocupação do espaço territorial tornam cada vez mais importante a manutenção do cadastro e o planejamento dos municípios com base em dados confiáveis.

No Brasil, paralelamente à expansão das cidades, está ocorrendo o agravamento dos problemas sociais e ambientais. A ocupação desordenada é um importante fator dessa degradação socioambiental. As áreas ocupadas de forma desordenada não permitem a definição dos limites das parcelas privadas e públicas, nem o controle sobre a exploração dos recursos naturais. Quando a ocupação do território cresce de forma descontrolada, ela gera prejuízos ambientais, sociais e econômicos.

O Cadastro contendo informações precisas permite calcular a degradação ambiental com solidez e compreender a situação socioeconômica dos agricultores. $\mathrm{O}$ cadastro deve aportar informações sobre as características existentes em cada parcela, possibilitando uma análise dessa ocupação e de seus impactos sobre o ambiente. Somente um cadastro preciso e constantemente atualizado oferece informações que auxiliam a compreender as tendências 
de crescimento da ocupação e, se necessário, intervir nos aspectos considerados prejudiciais ao meio ambiente e à maioria da população.

O Cadastro de Imóveis Rurais precisa ser um meio lógico e padronizado de relacionar bases de dados alfanuméricos e cartográficos originadas em diferentes instituições de gestão. A unificação dos esforços cadastrais permite considerar as características socioambientais de uma região, estado ou município, identificar problemas ambientais e de demarcação fundiária, conflitos no uso do solo e, assim, definir políticas públicas coerentes.

Os sistemas cadastrais são ferramentas de gestão eficientes e passíveis de implantação por parte do poder público.Sua exploração pode contribuir para a justiça socioambiental em nosso país. Observando a evolução da legislação brasileira relacionada ao Cadastro Rural, é possível perceber que houve progressos tanto no que se refere a

\section{Referências}

Araújo, S. M. V. G. de; Juras, I. A. G. M. Debate sobre a nova lei florestal: análise dos textos aprovados na câmara e no senado. In: Comitê Brasil em Defesa das Florestas e do Desenvolvimento Sustentável (Org.). Código Florestal e a ciência: o que nossos legisladores ainda precisam saber. Brasília: Comitê Brasil, 2012. p. 105-116.

Brito, J. P. M. Apreciações e reflexões sobre a Norma Técnica para Georreferenciamento de Imóveis Rurais. Florianópolis, Dissertação (Mestrado em Engenharia Civil) - Universidade Federal de Santa Catarina, 2005.

Camargo, F. Os rumos do Cadastro Ambiental Rural (CAR) precisam mudar. 2013. Instituto Sócio Ambiental - ISA. Disponível em: <www.socioambiental.org>. Acesso em: dez. 2013.

Carneiro, A. F. T. Proposta de reforma cadastral visando à vinculação entre cadastro e Registro de Imóveis. Florianópolis, Tese (Doutorado em Engenharia de Produção) Universidade Federal de Santa Catarina, 2000. aspectos jurídicos quanto a aspectos tecnológicos. Porém, persiste o desafio de centralizar o cadastro em uma instituição federal forte e ágil na recepção, na atualização e na distribuição de dados aos demais órgãos interessados e à sociedade civil organizada. Para que isso ocorra, é necessário definir padrões nacionais para os produtos cadastrais (cartografia e dados alfanuméricos), possibilitando o intercâmbio de informações entre as diferentes instituições.

A superação dos principais desafios nessa área passa pelo aumento do número de profissionais técnicos de forma a acompanhar e fiscalizar a campo a veracidade dos dados fornecidos pelos produtores rurais. Além disso, o investimento em tecnologias e parcerias com institutos de pesquisa e ensino por meio de projetos de extensão, principalmente em áreas de unidades de conservação e territórios de populações tradicionais e indígenas, representa uma alternativa sociotécnica pouco utilizada no país.

Clay, J. World Agriculture and the Environment. Washington: Island Press, 2004.

Demsetz, H. Toward a theory of property rights. American Economic Review, 57, 347-359, 1967. Disponível em: <http://www.econ.ucsb.edu/ tedb/Courses/Ec100C/ Readings/Demsetz_Property_Rights.pdf $>$. Acesso em dez. 2014.

Eberl, H. K. D. Sistemas Cadastrales. México: Editorial Concepto. 1982.

FAO. A new framework for conservation-effective land management and desertification control in Latin America and the Caribbean Guidelines for the preparation and implementation of National Action Programs. Roma, 1998. Disponível em: <http:/www.fao.org/docrep/W9298E/ W9298E00.htm>. Acesso em abr. 2016.

Freitas, E. O. O INCRA e a função social ambiental da propriedade rural: Direito e práticas em vistorias no Rio de 
Janeiro. Rio de Janeiro, Dissertação (Mestrado em Sociologia e Direito) - Universidade Federal Fluminense, 2007.

Girardi, E. P. Proposição teórico-metodológica de uma Cartografia Geográfica Crítica e sua aplicação no desenvolvimento do Atlas da Questão Agrária Brasileira. Presidente Prudente, Tese (Doutorado em Geografia) - Faculdade de Ciências e Tecnologia, Universidade Estadual Paulista, 2008.

Gordon, H. S. The economic theory of a common property resource: the fishery. Journal of Political Economy, 62, 124142, 1954. Disponível em: <http://herzog.economia.unam. $\mathrm{mx} /$ profesores/blopez/bienestar-ScottGordonFisheries. pdf>. Acesso em dez. 2014.

Guedes, S. N. R.; Reydon, B. P. Direitos de propriedade da terra rural no Brasil: uma proposta institucionalista para ampliar a governança fundiária. Rev. Econ. Sociol. Rural, 50(3), 525-544, 2012. Disponível em: <http://www.scielo.br/scielo.php?pid=S0103-20032012000300008\&script=sci_arttext>

Hardin, G. The tragedy of the commons. Science, 162, 1243-1248, 1968.

Larsson, G. Land Registration and Cadastral Systems. New York: Longman Scientific and Technical, 1996.

Laudares, S. S. de A.; Silva, K. G. da; Borges, L. A. C. Cadastro Ambiental Rural: uma análise da nova ferramenta para regularização ambiental no Brasil. Desenvolvimento e Meio Ambiente, 31, 111-122, 2014. Disponível em: $<$ http://ojs.c3sl.ufpr.br/ojs/index.php/made/article/viewFile/33743/23043>
Loch, C.; Erba, D. A. Cadastro Técnico Multifinalitário Rural e Urbano. Cleveland: Lincoln Institut of Land Policy, 2007.

Marighella, E. T. A questão agrária: textos dos anos sessenta. São Paulo: Editora Brasil Debates, 1980.

Martins, J. S. Os camponeses e a politica no Brasil. Petrópolis: Vozes, 1995.

Medeiros, L.S. História dos movimentos sociais no campo. Rio de Janeiro: Fase, 2002.

Muritiba, M. J. S; Alencar, C. M. M. de. Luta pela terra, reforma agrária e neoliberalismo. In: Anais do Congresso da Sociedade Brasileira de Economia, Administração e Sociologia Rural. Londrina, 2007.

Oliveira, A. U. O nó da questão agrária em Mato Grosso do Sul. In: Almeida, R. A. (Org.). A questão agrária em Mato Grosso do Sul: uma visão multidisciplinar. Campo Grande, 2008. p. 5-14.

Shigunov, T. Conexão entre o cadastro e o registro público de imóveis: análise crítica visando à aplicação da Lei $\mathrm{n}$ 10.267/01. Florianópolis, Dissertação (Mestrado em Engenharia Civil) - Universidade Federal de Santa Catarina, 2005.

Valor Econômico. Estados do Nordeste apresentam os índices mais baixos de adesão ao CAR. 30 mar. 2016. <http:// www.valor.com.br/agro/4504530/estados-do-nordeste-apresentam-os-indices-mais-baixos-de-adesao-ao-car>. Acesso em: abr. 2016. 